My thanks are due to Major G. J. Cunningham, M.B.E., R.A.M.C., for constant co-operation and advice and to Brigadier Harold C. Edwards, A.M.S., for permission to publish this paper. It is regretted that literature later than April, 1945 , was not available in this Theatre of War at the time of writing.

\title{
BIBLIOGRAPHY
}

1. Bentley, F. H. and Scott Thomson, Brit. Med. Jl., April 7. 1945.

2. RYCROFT, B. W.-Brit. Jl. Ophthal., Vol. XXIX, February, 1945.

3. RAMMELKAMPF, C. H. and KeEFER, C. S.-Ji. Clin. Invest., Vol. XXII, p. 425, May, 1943.

4. Salter, W. T.-New England Jl. Med., Vol. CCXXXI, p. 651, November 9, 1944.

5. LeOPOLd, I. H. and Lamotte.-Arch. Ophthal., Vol. XXXIII, i, 1935.

6. von Sallmann., L. and MeYer, K.-Arch. Ophthal., Vol. XXXI, i, 1944.

7. von SAllmann, L. and DI GRAN DI, J.-Arch. Ophthal., Vol. XXXII, p. 3, 1944.

8. Dunnington, J. H. and von Sallman N, L.-Arch. Ophthal., Vol. XXXII, p. 5, 1944.

9. Bellows, J. G.-Amer. Jl. Ophthal., Vol. XXVII, p. 11, 1944.

10. von SallmanN, L.-Arch. Ophthal., Vol. XXX, p. 426, 1943.

11. von SALLMANN and MEYER, K.-Arch. Ophthal., Vol. XXXI, p. 1, 1944.

12. LEOPOLD, I. H.-Arch. Ophthal., Vol. XXXIII, p. 3, 1945.

13. von Sallmann, L., MeYer, K. and Di Grand, J.-Arch. Ophthal., Vol. XXXII, p. 3, 1944.

14. Florey, H. W. and Jennings, M. A.-Brit. Jl. Exper. Path., Vol. XXIII, p. $120,1942$.

15. HerRelL, W. E. and Nicholls, D. R.-Jl. Amer.Med. Assoc., Vol. XVIII, p. $313,1943$.

16. Struble, G. C. and Bellows, J. G.-Jl. Amer. Med. Assoc., Vol. CXXV, p. $685,1944$.

17. ABRAHAM, E. P. et alia.-Lancet, Vol. II, p. 177.

18. Abraham, E. P. and Chain, E.-Nature, Vol. CXLVI, p. 837, 1940.

19. Rammelkampf, C. H. and Maxon, T.-Proc. Soc. Exp.Biol. N.Y., Vol. LI, p. 386.

20. Florey, H. W. and Jennings, M.-A.-Brit. Jl. Surg., special penicillin number.

21. Garrod, L. P. and Heatley, N; G.-Brit. Jl. Surg., special penicillin number.

\section{PENICILLIN IN OPHTHALMOLOGY* An interim review}

BY

\section{ARNOLD SORSBY}

LONDON

\section{1.-Ocular pharmacology of penicillin \\ Tolerance}

Penicillin in current clinical use is adequately standardised as regards potency, but is still largely an impure product so that a final assessment of the ocular tolerance to this drug as distinct from the available mixtures, is not possible at the present. The following data must therefore be treated with some reserve,

\footnotetext{
* Based on a lecture delivered at the Royal College of Surgeons, May 29, 1945.
} 
though they may be taken to apply to the penicillin in current use (which contains only $10-20$ per cent. of pure penicillin).

(a) Application to the conjunctiva and cornea.-In the rabbit drops of the isotonic saline solution of sodium penicillin in a concentration of 10,000 units per c.c. instilled every 5 minutes for an hour produced no obvious discomfort nor any objective evidence of irritability or damage to the corneal epithelium (as determined by fluorescein staining and examination with the slitlamp.) In contrast there were a number of stained areas 18 hours after a single instillation of drops of penicillin in a concentration of 20,000 units per c.c. In man drops in a concentration of 5,000 units per c.c. are well tolerated by most patients, though some complain of a stinging sensation when the drops are first instilled, whilst repeated application produces some reddening of the conjunctiva in most patients. In contrast drops in a concentration of 2,500 units are generally well tolerated.

Sodium penicillin can be instilled in the form of lamellae containing 250 units, but the base appears to be of some importance. Gelatine lamellae do not dissolve readily, whilst Parke Davis oculets which dissolve almost instantaneously invariably produce a transitory stinging sensation. Lamellae made of lactose (Neely \& Cross, 1945) dissolve less readily, but it has still to be established that penicillin so instilled persists in the conjunctiva longer than drops do.

(b) Subconjunctival injection.-In the rabbit subconjunctival injection of sodium penicillin in doses of 2,500 and 5,000 units dissolved in 0.25 c.c. of water produces no irritation. The yellowish subconjunctival bleb is readily absorbed, leaving no trace of discoloration or irritation after 18 hours. In man 1,250 units injected in 0.5 c.c. of isotonic saline produces a transitory stinging sensation; after 24 hours there is considerable conjunctival hyperaemia over an area somewhat larger than the original bleb. A second injection at this stage is distinctly painful, but after three days is almost as well tolerated as the original injection. Injections containing 5-600 units are well tolerated, and can be repeated daily without much discomfort.

(c) Injection into the anterior chamber.-In the rabbit injection of 200 units of penicillin in 0.2 c.c. of isotonic saline into the anterior chamber is fairly well tolerated. Within 24 hours there is some exudative reaction at the pupil margin-distinctly more than the mild reaction noticeable with almost any injection into the animal's anterior chamber. This reaction is transitory and within 3 days it leaves no trace.

In contrast injection of 2,000 units leads to a marked iritis.

(It is not easy to be sure of the actual amount injected, as almost invariably there is some leakage from the puncture wound.)

(d) Intravitreal injection.- In the rabbit the control eye into 
which 0.2 c.c. of sterile water had been injected; may show no changes or a definite vitreous opacity. The injection of 375,750 , 1,500 and 2,000 units of sodium or calcium penicillin dissolved in 0.2 c.c. of water or isotonic saline is badly borne. The smaller amounts produce gross. yellow vitreous opacities whilst with 1,500 units dense yellow fibrous bands develop within a week; in two out of six eyes thus treated the process continued till the globe became. a shrunken mass.

For three or four days after the injection the vitreous is generally too hazy to allow any fundus details to be observed. Subsequently the opacity is more localized and gross fundus disturbances downwards (apparently from penicillin dripping down) are noticeable. In 2 eyes a white area or atrophy simulating a typical choroidal coloboma was observed.

Substantially similar results are reported by other observers in the scattered and occasionally indirect literature.

(a) Tolerance of the conjunctiva and cornea.-According to Struble and Bellows (1944) drops containing penicillin in a concentration of 20,000 units per c.c. are well tolerated by the rabbit eye ; in man the use of a concentration of 10,000 units per c.c. produced no corneal damage. A concentration of 10,000 units per c.c. was used by Keyes (1944) with good result at 2-hourly intervals for 7 days. Penicillin in ointment form 500 units per gram of Lanette Wax S.X. was found superior to drops in a concentration of 500 units per c.c. by Crawford and King (1944), but Milner. (1944) found Lanette Wax ointment containing 100 units per gram more irritating than drops of 500 units per.c.c. In [?] one case Rycroft (1945) used penicillin in powder form at 3-hourly intervals with apparently good tolerance, whilst Juler and Young (1945) used sodium penicillin in crystal form for septic ulcers of the cornea.

(b) Tolerance to subconjunctival injection.-In the rabbit subconjunctival injection of penicillin in doses up to 2,500 units dissolved in 0.25 c.c. of isotonic saline is well tolerated, but some chemosis develops on the injection of 5,000 units (Struble and Bellows, 1944). In man La Rocca (1945) gave daily subconjunctival injections in progressively increasing doses, ranging from 50 to 1,000 units.

(c) Tolerance to injections into the anterior chamber.-Clinical use of penicillin instilled into the anterior chamber is reported by Cashell (1944), Grant (1944), La Rocca (1945), Mietus (1945) and Rycroft (1945). Cashell irrigated the anterior chamber in two cases of perforating injuries [? leaving one drop of penicillin in a concentration of 500 units per c.c.]. Grant, La Rocca and Mietus each report single cases in which about 50 units of penicillin were introduced with good results into the anterior chamber 
in perforating injuries. In no case was it necessary to repeat the injection. (La Rocca "forced" 50 units into the anterior chamber; Grant and Mietus introduced 0.25 c.c. of a solution containing 250 units per c.c.) Rycroft replaced 2 minims of aqueous by an equal quantity of water containing 2,000 units of penicillin; this procedure was carried out in 2 patients and was well tolerated.

(d) Tolerance of the vitreous to penicillin.-Von Sallmann, Meyer and Grandi (1944) report that 0.2 c.c. of a solution containing $25 \mathrm{mgr}$. (approximately $250-375$ units) of highly purified penicillin (i.e., a total amount of 50-75 units) produced a slight and transitory reaction on injection into the vitreous. Crude penicillin was more irritating, and more readily produced visible fundus changes seen histologically as damage to the retina. A second injection greatly increased the damage, the lens also becoming affected. On the other hand Rycroft (1945) holds the injection of 2,000 units (dissolved in 2 minims of water) into the vitreous was well tolerated in 3 patients, as was an injection of 5,000 units in a single case. The report by Leopold (1945) on the effect of penicillin in experimental infections of the vitreous suggests that the infected rabbit eye tolerates concentrations as high as 2,500 units.

\section{Concentration in ocular tissues}

Tears : In man no penicillin has been detected in the tears when the drug is injected intravenously, intramuscularly or subcutaneously (Rammelkampf and Keefer, 1943). A similarly negative finding is reported for the cat by Florey and his associates, but Struble and Bellows found penicillin in the tears of dogs which had received a massive intravenous dose.

1. Concentration in the eye after systemic injection of penicillin.-In rabbits the injection of $20 \mathrm{mgs}$. (approximately $2-3,000$ units) of penicillin per kilo of bodyweight, produces a very much lower level of concentration in the aqueous compared with the blood concentration, and there was no inhibitory effect on bacteria in the aqueous withdrawn after 15 minutes; primary aqueous at 30 and 45 minutes showed moderate antibacterial action; secondary aqueous withdrawn 45 and 60 minutes after injection (and 30 minutes after the first paracentesis) showed a distinctly higher concentration of penicillin. No antibacterial activity was noted in the vitreous (as also in cerebro-spinal fluid) taken 45,60 and 75 minutes after the injection of penicillin (v. Sallmann and Meyer, 1944). Leopold and La Motte (1945) could not detect any penicillin in the aqueous of rabbits examined 15, 45 and 105 minutes after intramuscular injection of 1,500 units per kilo of bodyweight.

In the dog Struble and Bellows (1944) found that penicillin 
reaches the ocular tissues readily after a single massive dose $(12,800$ units per kilo of bodyweight). Within 15 minutes the penicillin was at its highest concentration in the chorio-retinal tissues and extra-ocular muscles. In the less vascularised tissues (conjunctiva, cornea and sclera) and in the aqueous there was an initial sharp rise within the first 15 minutes and concentration continued to increase slowly until the end of the 1st hour. Barely a trace of penicillin remained in the eyeball after 3 hours. The concentration of penicillin in the tissues, listed in decreasing order was: extra-ocular muscles; sclera, conjunctiva, tears, chorio-retinal layer, aqueous, vitreous and cornea; there'was none in the lens. When these observers used a dose more nearly that used in clinical work, they found no antibacterial activity in the blood tested at hourly intervals, and in the ocular tissues tested at the end of $3,4,5$ and 6 hours after slow intravenous drip, or several intramuscular injections.

Leopold (1945) could not detect any penicillin in the vitreous of rabbits that had been given 4,000 units per kilo of bodyweight. The injections were made intramuscularly and intravenously, and the determinations of vitreous concentration carried out at intervals ranging from 15 minutes to 4 hours; the addition of gelatin and a vasconstrictor substance to the intramuscularly injected penicillin did not produce any effect, though there was a slower excretion of penicillin from the body. The preliminary injection of histamine into the vitreous produced a barely perceptible concentration of penicillin in two out of 12 experiments and a somewhat higher concentration in some of the rabbits whose anterior chambers had previously been grossly infected by the introduction of staphylococci.

Rycroft (1945) gives the following data on man : 1,500 [? 15,000] units of penicillin were injected intramuscularly in 2 c.c. of water administered every 3 hours. Five patients were moribund, and the tests for the presence of penicillin in the eyes were carried out $35,19,7,4$ and 6 hours after the last administration. In none of these patients did the aqueous or vitreous show any antibacterial activity. (The last two patients in this series had received 390,000 units in several doses and 30,000 units in one dose respectively, and their eyes had been removed 3 hours and 2 hours respectively after death.) In two moribund patients with grossly injured eyes, essentially negative results were likewise obtained when a penicillin assay was done 13 hours and 3 hours after the last dose, though it is worth noting that in this last case, which had received a single large dose of 30,000 units, slight bacteriostasis is reported for both the aqueous and vitreous. In 5 more patients with injured eyes which were excised (the patients' general condition being good) the aqueous and vitreous were tested in 2 cases $\frac{1}{2}$ hour, in 2 more 1 hour and in 1 case 2 hours after the last 
injection. Here too no anti-bacterial effect was seen in the aqueous and vitreous. All these patients had received 30,000 units of penicillin in 2 doses at an interval of about 2 hours.

2. Concentration after local application.-1. Application of drops. Von Sallmann and Meyer (1944) obtained "erratic results" in 2 instances, and in 4 experiments no inhibitory activity of the aqueous could be detected. Leopold and La Motte (1945) report to the same effect. Struble and Bellows (1944) introduced into the conjunctival sac an excess of solution containing 20,000 units of penicillin per c.c. of isotonic salline; " the lids were clamped sufficiently tight to prevent an escape of the fluid." The penicillin penetrated readily through the cornea and the aqueous showed a value of 3.32 units per c.c. in 30 minutes, a level maintained with but little change for $1 \frac{1}{2}$ hours, but increasing to $14 \cdot 2$ units per c.c. by 3 hours. The concentration of the drug in the cornea, iris and ciliary body was also high. The following table from Bellows (1944) gives the essential data :-

Concentration of Penicillin in the globe after constant corneal baths. $\quad(20,000$ units per c.c. $)$

\begin{tabular}{|c|c|c|c|c|c|}
\hline \multirow[b]{2}{*}{ Aqueous ... } & \multirow[b]{2}{*}{$\ldots$} & & \multicolumn{3}{|c|}{$\begin{array}{l}\text { Concentration in Oxford Units } \\
\text { per gr. or c.c. }\end{array}$} \\
\hline & & $\therefore$ & $\begin{array}{c}0.5 \text { hour. } \\
3.32\end{array}$ & $\begin{array}{c}1 \text { hour. } \\
4 \cdot 18\end{array}$ & $\begin{array}{c}3 \text { hours } \\
14.2\end{array}$ \\
\hline Conjunctiva & $\therefore$ & $\ldots$ & $114 \cdot 11$ & $177 \cdot 63$ & $26 \cdot 34$ \\
\hline Cornea .... & $\ldots$ & $\ldots$ & $46 \cdot 23$ & $90 \cdot 42$ & $27 \cdot 47$ \\
\hline Iris and Ciliary & Body & $\ldots$ & $30 \cdot 49$ & $35 \cdot 0$ & $9 \cdot 18$ \\
\hline Vitreous $\ldots$ & $\therefore$ & $\ldots$ & 0.92 & 1.95 & Trace \\
\hline Sclera $\quad \ldots$ & $\ldots$ & $\ldots$ & 39.76 & $57 \cdot 13$ & $?^{-}$ \\
\hline Posterior uvea a & and ret & & Trace & Trace & ? \\
\hline
\end{tabular}

There was no penicillin in the lens, but some could be detected in the vitreous. It should be noted that depletion from the anterior chamber is considerably slower than from the blood-a point also brought out by v. Sallmann and Meyer.

2. Application of ointments. V. Sallmann and Meyer, who could not obtain any bacteriostatic effect with the aqueous of rabbits receiving penicillin in drop forms, were also unable to obtain any results when ointments instead of drops were used. Leopold and La Motte likewise did not find ointments any more effective than drops.

3. Subconjunctival injections. The level of penicillin in the various ocular tissues is high when the drug is introduced subconjunctivally. For the anterior segment of the eye it is many 
times higher than that obtained by the intravenous route or by local application. One and a half to 3 hours after subconjunctival injection of 2,500 units the following values were obtained by Struble and Bellows.

Cornea : 28 units per gr. Vitreous 1.95 units; iris and ciliary body $10 \cdot 8$ to $26 \cdot 3$ units; sclera as a whole $163 \cdot 2$ to 194.7 ; posterior part of sclera 92.5 to 93.3 ; conjunctiva 106 to 449 . After 3 hours most of the ocular tissues tested were essentially negative except for slight amounts in the aqueous and vitreous humours.

Leopold (1945) gives the following values :-

When 2,500 units of penicillin (in 0.25 c.c. of isotonic saline) are injected subconjunctivally in the rabbit penicillin could not be detected in the vitreous 15 minutes after the injection; 0.078 units per c.c. was present 30 minutes later, and the same values were obtained 105 and 180 minutes after in jection. Considerably higher values were found if the anterior chamber had first been grossly infected by injection of staphylococcus aureus $(0.128,0.510,0.250$ and 0.250 units per c.c. $15,45,105$ and 180 minutes respectively after subconjunctival injection).

4. Injection into the anterior chamber. No data appear to be available on the date of excretion of penicillin injected into the anterior chamber, but Leopold (1945) has shown that the concentration in the vitreous at $15,45,105,180$ and 240 minutes after injection of 500 units (in $0.25 \mathrm{c.c}$. isotonic saline) into the anterior chamber is much higher than that obtained by the injection of 2,500 units subconjunctivally. 'The highest concentration was at 105 minutes after injection. In rabbits that had undergone a broad iridectomy the concentration-initially the same-tended to increase after 105 minutes. A distinctly higher concentration in * the vitreous was obtained in rabbits with grossly infected anterior chambers.

5. Injection into the vitreous. When 0.2 c.c. of a solution of penicillin containing $2.5 \mathrm{mg}$. per c.c. (2,500 units per c.c.) is injected into the vitreous a high concentration was still present at the end of six hours (between 180 to 480 microgram per c.c.); at 12 hours the concentration had declined to 45 to 67.5 micrograms per c.c.; after 24 hours it had declined to 45 micrograms-almost 4 times the concentration needed to inhibit the growth of a testtube sulture of pneumococcus type III in a dilution of $10^{-4}(\mathrm{v}$. Sallmann, Meyer and Di Grandi, 1944). (Intravitreal injection of sodium sulphacetamide also maintained high levels of concentration.)

In a case recorded by Rycroft (1945) there was still a " high concentration of penicillin " 2 days after 5,000 units had been injected.

6. Instillation into the conjunctival sac : effect of (a) modifying 
factors (wetting agents, corneal baths, iontophoresis, ointment bases) and (b) corneal abrasion and ulcer.

(a) Wetting agents do not increase the penetration of penicillin through the cornea into the aqueous (v. Sallmann and Meyer). A corneal bath is, however, effective (v. Sallmann and Meyer, Struble and Bellows), and iontophoresis still more effective, both in producing higher concentrations of penicillin in the anterior chamber and in maintaining these higher levels. When ointments are used the base is of importance, as the following table from' Bellows (1944) shows :-

Effect of various bases upon the penetration of penicillin through the cornea. $\quad(25,000$ units per gram base.)

\begin{tabular}{|c|c|c|c|c|}
\hline & $\begin{array}{l}\text { Simple } \\
\text { Ointment }\end{array}$ & $\begin{array}{l}\text { Oil-in-water } \\
\text { Emulsion }\end{array}$ & $\begin{array}{l}\text { "Vanishing" } \\
\text { type Stearate }\end{array}$ & $\begin{array}{l}\text { Lubricating } \\
\text { Jelly }\end{array}$ \\
\hline $\begin{array}{l}\text { Penicillin in aqueous } \\
\text { after } 1 \text { hour } \ldots\end{array}$ & 0.42 . & 0.38 & $3.43^{*}$ & 0.05 \\
\hline
\end{tabular}

(b) In the presence of a corneal abrasion or ulcer penicillin penetrates readily through the cornea into the anterior chamber. Aqueous withdrawn 15, 45 and 105 minutes after the intramuscular injection into rabbits of 1,500 units per kiloweights show the following concentrations respectively: $0.4,0 \cdot 15$ and $0 \cdot 15$ units per c.c. if there is an experimental corneal lesion against none in animals with normal corneae. Somewhat similar results are obtained with local applications: In the intact animal the aqueous shows no antibacterial action when withdrawn at 15, 45 and 105 minutes after instillation of drops (500 units per c.c.) or ointment (500 units per gram). When the corneae are abraded, drops give the following concentrations in the aqueous at the times indicated : $1.5,1.5$ and 0.6 units per c.c.; inflamed corneae give a somewhat lower concentration; solutions give a higher aqueous concentration than ointments (Leopold and La Motte, 1945).

\section{2.-Penicillin in experimental infections}

1. Corneal infections.-Robson and Scott (1943.) report on the use of penicillin in experimental corneal lesions produced in the rabbit by a strain of staphylococcus aureus and by pneumococcus type XIX. Leopold, Holmes and La Motte (1945) studied the effect of penicillin both by local application and by intramuscular injection in corneal infection due to a bacillus allied to the Friedlander bacillus.

Staphylococcal infections. Penicillin [? concentration] was instilled 1 hour after infection and continued hourly for 48 hours 
and thereafter hourly during the day only. Fourteen out of 17 eyes treated suffered slight or negligible damage, against moderate or severe damage in all but one of the control eyes. When treatment was started 24 hours after the infection, it was almost without effect.

Pneumococcal infections. Penicillin was instilled hourly for 36 hours and then hourly by day for about 3 days. Twenty-two of 28 eyes treated within 1,6 or 12 hours after infection showed only very slight or slight lesions, against severe lesions in all the untreated eyes. Even when treatment was started at 24 hours there was some effect- 8 out of 14 lesions were slight, while the lesions in all the control eyes were severe.

Infection due to a gram-negative rod simulating the Friedlander bacillus, but sensitive to penicillin in vitro:-

(a) Twelve rabbits were treated 2 hours after the infection by penicillin drops having a concentration of 500 units per c.c. applied hourly for 11 hours on the first day and after a treatment-free interval of 11 hours again hourly for a further 13 hours. On the third day penicillin was instilled only 4 times during the 24 hours.

(b) Three rabbits were treated by intramuscular injection of 250 units per kilo of bodyweight. The injections were begun 2 hours after the infection and were given at 2 hourly intervals for 3 days, except during the 8 hours after midnight.

The untreated eyes and the eyes of the three rabbits treated by intramuscular injections all showed severe lesions, in contrast to barely perceptible reactions in the eyes treated by local applications.

A similar experiment carried out with the first treatment delayed for 24 hours gave essentially the same results. The untreated eyes and the eyes of rabbits treated by intramuscular in jections showed severe lesions, whilst the eyes treated locally did much better, though not so well as those in the first series (in which treatment was begun 2 hours after the infection).

2. Inoculation into the Anterior Chamber.-1. Pneumococcus. V. Sallmann (1943) reports on infection with pneumococcus types 3,7 and 10 . Penicillin in solutions $0 \cdot 1$ per cent. and 0.25 per cent. was applied by corneal baths and iontophoresis; higher concentrations were found to damage the corneal epithelium. In general 0.05 c.c. of a $10^{-4}$ dilution of a 24 hours broth culture was injected into the anterior chamber. Treatment was started 6 and 12 hours after inoculation. Pneumococcus type VII gave the most violent initial reaction.

Type III. Five eyes treated six hours after inoculation and continued for 2 days (the treatment being sodium penicillin applied by iontophoresis or by corneal bath) all recovered (in contrast to six eyes, all lost, when treated by sodium sulphadiazine iontophoresis and sulphadiazine feeding, and 5 control eyes, also all 
lost). Eleven out of 12 eyes first treated 12-13 hours after inoculation also recovered (against 2 out of 3 controls). Nine out of 12 eyes in which the lens was deliberately injured at the time of inoculation recovered when treated after 6 hours (against none of 3 controls).

Type X. Six eyes treated within 6 hours of inoculation all recovered (against 1 out of 12 controls, six of which had received sodium sulphadiazine iontophoresis and sulphadiazine feeding and 4 sulphadiazine feeding only). Five out of 6 eyes first treated 12-13 hours after inoculation also recovered (against none out of 2 controls). When the lens was also injured, none of the three control eyes recovered; but the 9 treated eyes all recovered with treatment begun after six hours.

Type VII. Treatment begun in 12 eyes $12-13$ hours after inoculation led to recovery in 9 eyes; the 4 controls were all lost.

2. Staphylococcus aureus. Inoculating 0.05 c.c. of a $10^{-4}$ culture of strains of staphylococcus aureus into the anterior chamber and at the same time deliberately injuring the lens, von Sallmann (1944a) obtained 15 recoveries in 24 infections by the use of sodium penicillin iontophoresis begun 6 to 7 hours after infection. The 19 control eyes were all lost, as were 12 out of 13 eyes in rabbits treated by the oral administration of sulphadiazine, and 18 out of 23 when sulphadiazine feeding was combined with sodium sulphadiazine iontophoresis. In a further series (v. Sallmann 1944b) there were 9 recoveries out of 12 eyes, and no better? results could be obtained by combining local penicillin therapy with sulphadiazine iontophoresis and feeding.

3. Cl. Welchii. Intralenticular injections of this organism in 8 eyes gave a destructive endophthalmitis not influenced by local penicillin therapy (nor by combined sulphadiazine therapy in 4 more eyes, and in 12 untreated control eyes). (v. Sallmann, 1944a.)

3. Inoculation of staphylococcus aureus into the vitreous.The injection into the vitreous of 0.05 c.c. of a 24 hours broth culture of staphylococcus aureus in a dilution of $10^{-4}$ or $10^{-5}(\mathrm{v}$. Sallmann, Meyer and Di Grandi, 1944) induced a destructive suppurative endophthalmitis in the rabbit, sometime fulminating and at times more slowly leading to the development of a vitreous abscess within 4 to 7 days. Histologically dense leucocytic infiltration with much destruction of the retina together with exudative retinal detachment were present within 30 hours of the infection. Twenty control eyes were all lost, as were all the 8 eyes treated within 6 hours by an intravitreal injection of $0 \cdot 2$ c.c. of 10 per cent. solution of sodium sulphacetamide. In contrast 10 eyes treated within 6 hours by either one or two intravitreal in jections of 0.2 c.c. of sodium penicillin in a concentration of 2,500 units per c.c. (i.e. 
500 units per injection), all recovered, as did 10 eyes first treated likewise 12 hours after the infection; 10 eyes in which treatment was begun 24 hours after the infection were all lost.

Though penicillin controlled the infection it appeared to have a somewhat deleterious effect on the vitreous, retina and lens, this effect being more marked with 2 intravitreal injections than one.

Earlier v. Sallmann (1943) had noted that penicillin iontophoresis did not check pneumococcal infection introduced into the anterior chamber, once the process had spread backward to the vitreous.

Leopold (1945) reports a comparative study on the effect of penicillin administered by different routes in experimental standard infection of the vitreous by staphylococcus aureus.

0.01 c.c. of a diluted 18 hours broth culture of staphylococcus aureus containing approximately 400 organisms was injected into each of the two eyes in 50 rabbits. Severe infection developed within 24 hours; the vitreous gradually became opaque and all untreated eyes were phthisical within 4 to 6 weeks. Where treatment was given it was started 2 hours after the inoculation.

(a) Intravenous administration of 4,000 units of penicillin per kilo of bodyweight : carried out in 6 rabbits at 2 hourly intervals for 72 hours. No therapeutic effect.

(b) Subconjunctival injection of 2,500 units in 0.25 c.c. of isotonic saline : carried out every 3 hours for 72 hours in the right eye of 6 rabbits. The six control eyes and 4 of the treated eyes were lost; the remaining 2 eyes showed partial control of the infection.

(c) Injection into the anterior chamber of 500 units of penicillin at 3 hourly intervals for 72 hours in the right eye of 6 rabbits. The six control eyes and 4 of the treated eyes were lost; the remaining two gave a fair response.

(d) Intravitreal injection of 2,500 units of penicillin : carried out once in the right eye of six rabbits. The six control eyes were all lost. All the six treated eyes were quiet after 4 weeks of observation, showing nothing beyond occasional vitreous opacities.

(e) Intravitreal injections of penicillin in quantities less than 2,500 units : 2 eyes received $2,000,1,000,500,250,50,25,10$ and 5 units each and 4 eyes 100 units each. All eyes receiving more than 1,000 units were as favourably influenced as those receiving 2,500 units, but only 2 eyes with lower dosage (one with 500 and one 250 units) responded as satisfactorily; yet even in the poorest result the beneficial effect of penicillin was obvious. 


\section{Clinical experiences}

1. Systemic administration.-As yet only a few reports are available. The following summary table shows the essential data:

\begin{tabular}{|c|c|c|c|c|}
\hline Author & Clinical condition & Treatment & Result & Remarks \\
\hline Mietus, 1945 & $\begin{array}{l}\text { Pellet injury to } \\
\text { eye with retained } \\
\text { F.B. Threatened } \\
\text { panophthalmitis }\end{array}$ & $\begin{array}{l}25,000 \text { units every } \\
3 \text { hours for } 42 \text { days }\end{array}$ & Recovery & - \\
\hline $\begin{array}{r}\text { Green and } \\
\text { Jakobovits, } \\
1945 \\
.\end{array}$ & $\begin{array}{l}\text { Suppurative en- } \\
\text { dophthalmitis } \\
\text { following catar- } \\
\text { act operation } 4 \\
\text { years previously, } \\
\text { complicated by } \\
\text { prolapse of iris. } \\
\text { Staphylococcal } \\
\text { infection }\end{array}$ & $\begin{array}{l}20,000 \text { units intra- } \\
\text { muscularly every } \\
3 \text { hours. Total : } \\
22 \text { injections }\end{array}$ & Recovery & $\begin{array}{l}\text { Case had } \\
\text { proved re- } \\
\text { fractory to } \\
\text { sulphona- } \\
\text { mides }\end{array}$ \\
\hline $\begin{array}{c}\text { Rycroft } \\
1945 \\
\end{array}$ & $\begin{array}{l}\text { War injury. } 10 \\
\text { F. Bs. extracted } \\
\text { with magnet. } \\
\text { Hypopyon with } \\
\text { yellow retro- } \\
\text { lenticular reflex } \\
2 \text { days later } \\
\text { - }\end{array}$ & $\begin{array}{l}15,000 \text { units intra- } \\
\text { muscularly every } \\
3 \text { hours. Total: } \\
500,000 \text { units. }\end{array}$ & $\begin{array}{l}\text { No improve- } \\
\text { ment }\end{array}$ & $\begin{array}{l}\text { When intra- } \\
\text { m u s c l a r } \\
\text { course com- } \\
\text { pleted } 30,000 \\
\text { units injected } \\
\text { into aqueous. } \\
\text { No response. } \\
\text { Finally im- } \\
\text { proved after } \\
\text { a course of } \\
\text { sulphathia- } \\
\text { zole }\end{array}$ \\
\hline$-\quad(b)$ & $\begin{array}{l}\text { War injury. In- } \\
\text { fected penetrat- } \\
\text { ing wound of } \\
\text { cornea. Hypop- } \\
\text { yon }\end{array}$ & $\begin{array}{l}15,000 \text { units intra- } \\
\text { muscularly every } \\
3 \text { hours, Total; } \\
500,000 \text { units }\end{array}$ & $\begin{array}{l}\text { No improve- } \\
\text { ment }\end{array}$ & $\begin{array}{l}\text { Preliminary } \\
\text { sulphathia- } \\
\text { zole and } \\
\text { T.A B. the- } \\
\text { rapy without } \\
\text { result }\end{array}$ \\
\hline Griffey, 1944 & $\begin{array}{l}\text { Gonococcal con- } \\
\text { junctivitis in a } \\
\text { man aged } 24 \\
\text { years }\end{array}$ & $\begin{array}{l}25,000 \text { units intra- } \\
\text { muscularly every } \\
3 \text { hours. Total: } \\
10 \text { injections }\end{array}$ & $\begin{array}{l}\text { R a pid } \\
\text { covery }\end{array}$ & $\begin{array}{l}\text { Previously } \\
\text { treated with } \\
\text { sulphathia- } \\
\text { zole when } \\
\text { urethritis } \\
\text { cleared, but } \\
\text { not the con- } \\
\text { junctivitis }\end{array}$ \\
\hline $\begin{array}{l}\text { Dunnington } \\
\text { and v. } \\
\text { Sallmann } \\
\text { (also re- } \\
\text { ported by } \\
\text { Elliot t), } \\
1944\end{array}$ & $\begin{array}{l}\text { Severe plastic } \\
\text { iritis developing } \\
\text { in the course of } \\
\text { sulphadiazine } \\
\text { treatment of } \\
\text { gonorrhoea }\end{array}$ & $\begin{array}{l}15,000 \text { units intra. } \\
\text { venously every } 3 \\
\text { hours for } 5 \text { days }\end{array}$ & $\begin{array}{l}\text { Marked im- } \\
\text { provement } \\
\text { in } 48 \text { hours. } \\
\text { Total re- } \\
\text { covery in } \\
14 \text { days }\end{array}$ & $\begin{array}{l}\text { Local applica- } \\
\text { tion of peni- } \\
\text { cillin by ioni- } \\
\text { zation also } \\
\text { carried out }\end{array}$ \\
\hline & & & - & \\
\hline
\end{tabular}




\begin{tabular}{|c|c|c|c|c|}
\hline Author & Clinical condition & Treatment & Result & Remarks \\
\hline $\begin{array}{l}\text { Sievers et al. } \\
1944\end{array}$ & $\begin{array}{l}\text { Eight cases of } \\
\text { oph th a } 1 \mathrm{~m} \text { i a } \\
\text { neonatorum, } 2 \\
\text { being gonococcal }\end{array}$ & $\begin{array}{l}10,000 \text { units intra- } \\
\text { muscularly every } \\
3 \text { hours: Total } \\
\text { dosage }:- \\
1 \text { case } 60,000 \text { units } \\
1 \text { case } 120,000 \text { units } \\
1 \text { case } 230,000 \text { units } \\
1 \text { case } 2+0,000 \text { units } \\
1 \text { case } 330,000 \text { units } \\
3 \text { cases } 180,000 \text { units }\end{array}$ & $\begin{array}{l}\text { Six cases (un- } \\
\text { starred) re- } \\
\text { s p o n d ed } \\
\text { well within } \\
24 \text { hours }\end{array}$ & $\begin{array}{l}\text { The } 2 \text { failures } \\
\text { showed some } \\
\text { improvement } \\
\text { originally, } \\
\text { but relapsed }\end{array}$ \\
\hline $\begin{array}{l}\text { Bellows (a) } \\
1944 \\
\quad(b)\end{array}$ & $\begin{array}{l}\text { Two cases of } \\
\text { chronic exuda- } \\
\text { tive choroiditis } \\
\text { Gonococcal irido- } \\
\text { cyclitis }\end{array}$ & $\begin{array}{l}\text { Massive doses of } \\
\text { penicillin parent- } \\
\text { erally and locally }\end{array}$ & No response & 一 \\
\hline $\begin{array}{cc}\text { Berens } & (a) \\
& (b)\end{array}$ & $\begin{array}{l}\text { Choroiditis } \\
\text { Iridocyclitis }\end{array}$ & - - & No response & - \\
\hline $\begin{array}{c}\text { Somer ville- } \\
\text { Large, } 1945\end{array}$ & Iridocyclitis & - & No response & - \\
\hline $\begin{array}{l}\text { Goldberg } \\
1945\end{array}$ & $\begin{array}{l}\text { One case gonorr- } \\
\text { hoeal choroiditis } \\
\text { Five cases of cho- } \\
\text { roiditis-prob- } \\
\text { ably tuberculous }\end{array}$ & $\begin{array}{l}160,000 \text { units daily } \\
\text { for } 3 \text { days } \\
\text { ? same dose }\end{array}$ & $\begin{array}{l}\text { Go od re - } \\
\text { sponse } \\
\text { No response }\end{array}$ & - \\
\hline $\begin{array}{l}\text { Brücher }(a) \\
\quad 1944\end{array}$ & $\begin{array}{l}\text { Severe endoph- } \\
\text { thalmitis follow- } \\
\text { ing septic abor- } \\
\text { tion }\end{array}$ & $\begin{array}{l}15,000 \text { units intra- } \\
\text { muscularly every } \\
3 \text { hours for } 3 \text { days. } \\
\text { Total : } 400,000\end{array}$ & - & $\begin{array}{l}\text { Preliminary } \\
\text { sulphathia- } \\
\text { zole therapy } \\
\text { no response. } \\
\text { Rapid reco- } \\
\text { very under } \\
\text { penic illi n, } \\
\text { giving vision } \\
\text { of } 0.8 \text {. Sub- } \\
\text { sequently re- } \\
\text { tinal detach- } \\
\text { ment deve- } \\
\text { loped. Oper- } \\
\text { ation only } \\
\text { partially suc- } \\
\text { cessful } \\
\text { Good result }\end{array}$ \\
\hline (b) & ibid. & On same lines as $(a)$ & 一 & $\begin{array}{l}\text { Good result, } \\
\text { R e s i d u a } 1 \\
\text { vision } 0.3\end{array}$ \\
\hline$-\quad(d)$ & $\begin{array}{c}\text { ibid. } \\
\text { ibid., " } \begin{array}{c}\text { several } \\
\text { cases ", }\end{array}\end{array}$ & ditto & - & $\begin{array}{l}\text { Good result. } \\
R \text { e s i d u a } 1 \\
\text { vision } 0.8 \\
\text { No result }\end{array}$ \\
\hline
\end{tabular}

2. Intravitreal injections.-The only records available are those reported by Rycroft, who used this procedure in 4 cases.

1. Penetrating injury of cornea from barbed wire. Two days later there was infection of the corneal wound, hypopyon, iritis 
and local lens changes. A course of sulphathiazole and shock therapy produced some improvement; a subsequent course of $500,000^{\circ}$ units of penicillin intramuscularly gave no further improvement. Intravitreal injection of 2,000 units of sodium penicillin did not save the eye from enucleation.

2. Penetrating scleral wound from explosion of a Mills grenade. Two days later this was covered by a conjunctival flap at a casualty clearing station; six days after this the eye showed acute iritis and a yellow vitreous reflex. There was no P.L. and radiography showed an intra-ocular foreign ibody, which was removed the following day; turbid vitreous escaped and 2,000 units of penicillin injected. "Normal convalescence; the eye settled and became white, but the yellow vitreous reflex persisted. Tension normal to soft and vision No. P.L."' The vitreous and foreign body were both sterile.

3. Penetrating corneal wound from shell fragment. There was prolapse of iris, traumatic catàract and a large intra-ocular foreign body which was removed at a Mobile Unit. Six days later the vitreous showed gross infection and on the following day 5,000 units of sodium penicillin were injected into the vitreous. Two days after this the condition had so deteriorated as to call for excision of the eye; the vitreous was found sterile and still possessed a " high concentration of penicillin."

4. Limbal penetrating wound from splinter with iris prolapse. The iris prolapse was excised two days after the injury at a Mobile Unit. Seen 9 days after the operation, there was acute iritis, canary-yellow vitreous and an intra ocular foreign body, which was removed; an intravitreal injection of 2,000 units of penicillin was given. Three weeks subsequently: "eye quiet and white. Diffuse yellow reflex behind the lens infiltrating the vitreous. This appears to have increased since the operation. Tension soft. Vision faint P.L." 'Within a further fortnight the eye had to be excised because of pain and irritability; "globe shrinking rapidly." Both the vitreous and foreign body proved sterile.

3. Penicillin introduced into the anterior chamber.-La Rocca (1945) "forced" 50 units of penicillin into the anterior chamber of a patient suffering from a hypopyon ulcer resistant to sulphonamide and T.A.B. treatment (100 units were simultaneously injected subconjunctivally). On the following day the hypopyon had disappeared.

Cashell (1944) irrigated the anterior chamber with penicillin [? leaving' one drop of a solution containing 500 units per c.c.] in one case of perforating injury and in another of post-operative (cataract) infection. Except fớr anterior chamber lavage (and local penicillin therapy) " these eyes would undoubtedly have been lost from panophthalmitis."

Grant (1944) and Mietus (1945) both report the replacement of 
0.25 c.c. aqueous by $0: 25$ c.c. solution containing 250 units of penicillin per c.c. In Grant's case there was a penetrating wound with exudative iridocyclitis; recovery set in within 48 hours. In Mietus' case a perforating injury with prolapse of iris was followed by a severe iritis with hypopyon; 48 hours after the injection into the anterior chamber the eye was white.

Rycroft (1945) replaced 2 minims of aqueous by the same quantity of solution containing 2,000 units of penicillin. In one case of hypopyon keratitis there was no improvement; there was likewise no improvement in a second case of purulent infiltration of the cornea when penicillin solution was introduced into the aqueous and penicillin powder into the conjunctival sac. Both these cases had sustained war injuries.

4. Subconjunctival injection.-In a case of hypopyon keratitis treated by the injection of 50 units of penicillin into the anterior chamber, La Rocca added subconjunctival injections daily gradually working up to 1,000 units per injection. He also used subconjunctival injections, initially of 50 units but gradually. working up to 1,000 units in a case of absolute glaucoma with hypopyon ulcer. In the first case there was no corneal staining after 11 days, and likewise none in the second after 22 days. The hypopyon had disappeared within 24 hours and 7 days in the two cases respectively.

5. Local application of drops.-A large number of reports on the value of penicillin in various external infections of the eye are on record.

1. Ophthalmia neonatorum.-(a) Florey and Florey (1943) used penicillin (6-800 units per c.c.) hourly during the day and 2 hourly at night in 5 cases : 2 showing staphylococcus aureus, 1 B. Coli, 1 gonococcus and 1 an undetermined organism. All responded well within a week.

(b) Lemoine and Lemoine (1944) used penicillin in a concentration of 700 units per c.c. at hourly intervals in 1 case showing staphylococci. and streptococci, and obtained a cure within 3 days.

The gonococcal case in the series reported by the Floreys and the case recorded by the Lemoines had both previously been treated unsuccessfully by sulphonamides.

2. Gonococcal ophthalmia.-Bellows (1944) records a case of gonococcal ophthalmia in an adult cleared in 10 days by $\frac{1}{2}$-hourly instillation of penicillin [? concentration].

3. Acute conjunctivitis.-Abraham et al. in 1941 and Florey and Florey in 1943 had already noted the value of penicillin in 3 and 4 cases of acute conjunctivitis respectively. Bellows (1944), Crawford and King (1944), Cashell (1944), Milner (1944), and Palin (1944), extended these observations by records on $22,7,10$, 18 and an unspecified number respectively. Satisfactory results -cure within 12 hours to 10 days-were noted by all these 
observers and the organisms involved were: staph. aureus, streptococci, Koch-Weeks bacillus and some unidentified. The concentration used ranged from 200-2,500 units per c.c. Crawford and King noted 1 relapse in their series of 7 cases, and Milner 2 relapses in 18 cases; one of Milner's cases showing staph. albus appeared to have been made worse:

4. Subacute conjunctivitis. - In a series of 19 cases-17 due to staph. aureus-recorded by Florey and Florey (1943) there was 1 failure; as an average it took $2 \frac{1}{2}$ weeks to produce cure with penicillin in a concentration of $600-800$ units per c.c. Milner (1944) had 7 failures in 16 cases, some of these being non-organismal. Bellows (1944) obtained cure in 6 cases within $1-8$ days.

5. Acute conjunctivitis with superficial or marginal keratitis or corneal ulcer.-Florey and Florey (1943), Crawford and King (1944), and Bellows (1944) report on 6,12 and 3 cases respectively, and. Mietus (1945) on a single case. The organisms met were chiefly staph. aureus, but included 2 cases showing diphtheroids (Crawford and King). With the exception of a relapse in one case of staph. aureus infection, the results were good (cure in about $7 \frac{1}{2}-9$ days in the series recorded by Crawford and King). The concentration used was generally 250 units per c.c.

6. Corneal ulcer.-(a) Simple ulcer. Abraham et al. in 1941 noted a good result in a single case of staphylococcal corneal ulcer. Cashell (1944) obtained cure in 4-18 days in 8 cases showing staph. aureus, one staph. albus and one more showing Bacillus of Petit; penicillin was used in a concentration of 500 units per c.c. Keyes ((1.944) obtained a satisfactory result in two cases; a case with unidentified bacilli was treated with 250 units per c.c., and a case with staph. aureus by 1,000 units per c.c. Milner likewise had satisfactory results in 8 cases [? organism] using a concentration of 500 units per c.c. (or 100 units per gr. in ointment form).

(b) Dendritic ulcer. Milner (1944) could obtain no result in dendritic ulcer. Keyes (1944) observed improvement in 2 cases, but holds that this may have been due to hospitalization.

(c) Phlyctenular ulcer. Burr (1944) observed cure in 3 out of 4 cases treated with penicillin 500 units per c.c. (or 100 units per gram in ointment form). Recovery in 4 days, but with subsequent relapse, was noted in 1 case by Sampson (1944).

(d) Disciform keratitis. Negative results are reported by Milner.

(e) Recurrent marginal ulcer. In these too, MiIner could obtain no results, but Dunnington and v. Sallmann obtained a cure in 5 days by the use of 0.5 per cent. sodium penicillin in ointment form at 3 hourly interval.

(f) Hypopyon keratitis. A satisfactory result is noted by the Floreys (1943) in 1 case treated with drops $600-800$ units per c.c. (La Rocca, 1945, obtained a satisfactory result in 2 cases by the 
use of subconjunctival injections, with the addition of an injection of 50 units into the anterior chamber in 1 case.). In a substantial study on 23 cases of septic ulcer of the cornea, mostly complicated by the presence of hypopyon, Juler and Young (1945) obtained gratifying results in all but 4 cases. The organisms found were pneumococcus (5 cases), staphylococcus aureus (7 cases), streptococcus (5 cases), Morax-Axenfeld Bacillus ( 3 cases), pneumobacillus ( 2 cases) and Bacillus pyocyaneus ( 1 case). They used penicillin drops in a concentration of 500 units per c.c. at hourly intervals during the day and 2 hourly at night; in some of their cases they curetted the ulcer and applied solid pencillin in crystal form.

7. Blepharitis.-The Floreys (1943, Cashell (1944), Milner (1944) and Crawford and King (1944) report on series of 46, 20, 26 and 19 cases respectively. The causal organism was generally staph. aureus, but single cases showing the Morax-Axenfeld bacillus are included by Crawford and King and by Milner. Recovery between 3 to 15 days is noted by these observers ; penicillin was generally applied in the form of drops into the conjunctival sac. All observers, however, had some failures and relapses -an observation also made by Keyes. Florey, McFarlan and Mann (1945) report clinical recovery in 36 cases, improvement in 11 cases and failure in 1 case in a series treated by penicillin ointment containing 600-800 units per gram. Recovery generally took $3-10$ weeks.

8. Tráchoma.-Keyes (1944) obtained no result in a case of ? trachoma treated at 2 hourly intervals for 9 days by drops containing 1,000 units per c.c. Gilford (1945) found that 4 cases " subsided rapidly " under drops applied 3 hourly and containing 16,000 units per c.c. Milner (1944) and Bellows (1944) each report improvement in a doubtful case of trachoma:

9. Episcleritis.-A rapid response, followed by relapse, is noted in a case by Milner, who used penicillin in a concentration of 1,000 units per c.c. In 3 cases, Bellows found recovery in 24 hours once, and twice within a week.

10. Infected socket.-Satisfactory results are reported in single cases by the Floreys and Sampson. Burr likewise obtained a good result in 2 cases. Milner on the other hand found penicillin disappointing in several cases.

11. Dacryocystitis.-The Floreys obtained 3 successes in 6 cases by irrigation with penicillin 6-800 units per c.c. Milner injected the solution into the sac, whilst Cashell reports on 3 cases.

12. Herpes ophthalmicus.-Sampson (1944) obtained negative results.

13. Post-operative infection.-Dunnington and v. Sallmann (1944) applied penicillin locally in a case of incipient panophthalmitis noted on the first dressing of a cataract extraction in a 
diabetic. The eye ultimately had to be excised. They also obtained no result in a post-operative infection in a Lagrange operation, also in a diabetic; penicillin in this case had been applied in a corneal bath.

6. Personal experiences.-1. Penicillin in 85 cases of ophthalmia neonatorum.-Initially drops in a concentration of 500 units per c.c. were used in 8 cases; only 3 recovered. When a concentration of 1,000 units per c.c. was used 4 out of 7 recovered, and with 1,500 units per c.c. 6 out of 10 . When the concentration was increased to 2,500 units per c.c.- and the drops instilled at half-hourly intervals for 3 hours, then hourly for 24 hours and two hourly subsequently-21 cases out of 22 so treated recovered. None of these 21 cases took longer than 100 hours to show a clinical cure, and in 6 cases clinical cure was obtained within 3 to 24 hours.

Continuing the use of penicillin in a concentration of 2,500 units per c.c. a further 13 cases were treated with drops instilled at hourly intervals for 6 hours, then 2 hourly for 24 hours and subsequently at 3 hourly intervals; there was recovery in all cases in 4 to 60 hours, 4 of these cases showing clinical cure within 24 hours. There were, however, 2 relapses in this series. A final series of 25 cases was treated by intensive application of penicillin; drops were instilled at intervals of 5 minutes (no irrigation subsequent to the first one being found necessary) until all tendency to the formation of pus was suppressed; when all discharge had ceased penicillin was continued at half-hourly intervals till the eye was dry; thereafter it was instilled hourly for 12 hours and 2 hourly for a further 24 hours. In this series there were two failures, and 5 relapses after clinical cure, but of the cases that responded well no less than 13 showed clinical cure within 12 hours and a further 4 within $12-24$ hours.

The following summary table shows the time taken for a clinical cure in the successfully treated cases of the 3 series, submitted to the same concentration of penicillin (2,500 units per c.c.) but at different time scales.

\section{Penicillin drops in concentration of 2,500 units}

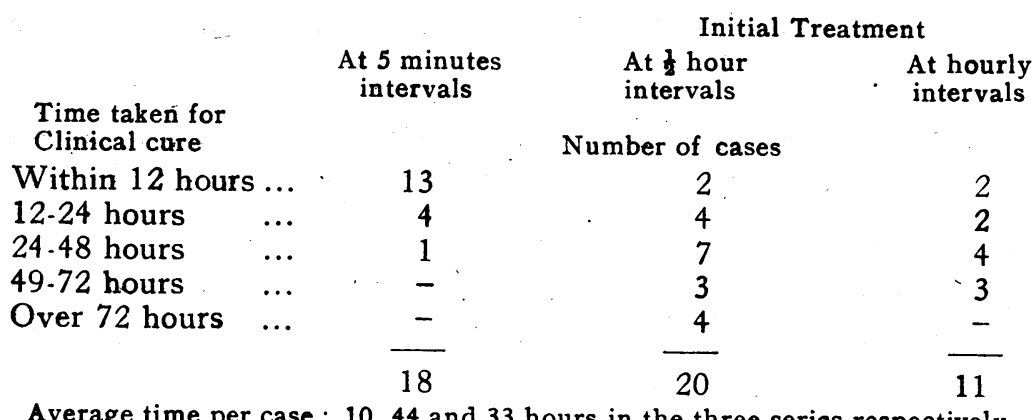


The whole series, of 60 cases treated by penicillin in a concentration of 2,500 units per c.c. is summarised in the two following tables, one showing the results in relation to severity and the other to causal organisms :-

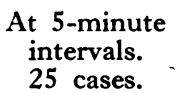

25 cases.

\author{
At half-hour \\ intervals. \\ 22 cases.
}

\section{At hourly intervals. 13 cases.}

\section{MILD}

6 cases: Clinical cure in 25 minutes to 21 hours. Average: 8 hours.

No failures.

No relapses.

5 cases: Clinical cure in 7-78 hours.

Average: 51 hours.

No failures.

No relapses.

\section{MODERATE}

13 cases: Clinical cure in 3 hours to 38 hours. Average (of 11 cases): 13 hours.

Two failures.

Four relapses.

1 cases: Clinical cure in 3 hours to 100 hours. Average : 46 hours.

No failures.

No relapses.

3 cases: Clinical cure in 4 hours to 56 hours. Average: 36 hours.

No failures.

No relapses.

5 cases: Clinical cure in 30 hours to 60 hours.

Average: 41 hours.

No failures.

Two relapses.

\section{SEVERE}

6 cases: Clinical cure in 4 hours to $16 \frac{1}{2}$ hours.

Average: 11 hours.

No failures.

One relapse.
6 cases: Clinical cure in 36 hours to 40 hours.

Average (of 5 cases): 37 hours.

One failure.

No relapses.
5 cases: Clinical cure in 4 hours to 34 hours.

Average: 16 hours.

No failures.

No relapses.

Efficacy in relation to causal organisms

\section{Initial treatment}

At 5 -minute
intervals.
25 cases.

\author{
At half-hour \\ intervals. \\ 22 cases.
}

\section{GONOCOCCUS}

5 cases : $1 \frac{1}{2}$ hours to $10 \frac{1}{2}$ hours. Average (of 4 cases): $7 \frac{1}{2}$ hours.

One failure.

No relapses.

8 cases: $5 \frac{3}{4}$ hours to 22 hours.

Average: $10 \frac{1}{2}$ hours.

No failures.

Three relapses.
5 cases : 24 hours to 40 hours.

Average (of 4 cases*): 35 hours.

No failures.

No relapses.

\section{STAPH. AUREUS}

5 cases: 3 hours to 60 hours.

Average : 20 hours.

No failures.

No relapses.

STAPH. ALBUS

4 cases : 27 hours to 43 hours.

Average : 37 hours.

No failures.

No relapses.
4 cases: 4 hours to 34 hours.

Average : 21 hours.

No failures.

No relapses.

1 case: 4 hours.

No failure.

No relapse. At hourly
intervals.
13 cases. 
At 5-minute intervals. 25 cases.

3 cases: 3 hours $3 \frac{1}{6}$ hours (in 2 cases).

One failure.

One relapse.
At half-hour

in tervals.

22 cases.

\section{DIPHTHEROIDS}

4 cases : 50 hours to 1001 case : 56 hours.

hours.

Average (of 3 cases): 83

hours.

One failure.

No relapse.
At hourly

intervals.

13 cases.

No failure.

No relapse.

\title{
HAEMOLYTIC STREPTOCOCCUS
}

1 case : 25 minutes.

No failure.

No relapse.

1 case : 33 hours.

No failure.

Relapse.

\section{GRAM-NEGATIVE DIPLOCOCCI}

1 case: 16 hours.

No failure.

No relapse.

1 case : 16 hours.

No failure.

No relapse.

\section{GRAM - POSITIVE COCCI}

\author{
1 case: 18 hours. \\ Average: - \\ No failure. \\ No relapse.
}

\section{NO ORGANISMS NOR INCLUSION BODIES}

1 case: $13 \frac{1}{2}$ hours.

2 cases: 12 hours and 70 hours respectively.

4 cases: 48 hours to 60 hours.

Average : 57 hours.

No failures.

No failure.

No relapse.

One relapse.

\section{VIRUS PRESUMED FROM PRESENCE OF INCLUSION BODIES}

4 cases: 3 hours to 382 cases: 78 hours and 2 cases: 30 and 38 hours hours.

Average: 16 hours.

No failures.

No relapses.

\section{0 respectively.}

Average : 89 hours.

No failures.

No relapses. respectively.

Average: -

No failure.

One relapse.

* One case is excluded as a corneal ulcer, present on admission, delayed a return to normal.

In this total of 60 cases there were therefore 1 failure in a series of 14 cases showing the gonococcus and 2 failures in a series of 8 cases showing diphtheroids; there were no failures in the 14 cases due to staph. aureus and in the 4 showing staph. albus, while the single cases due to str. haemolyticus, Friedlander's bacillus, Morax-Axenfeld bacillus; Gram-negative diplococci, and Grampositive cocci all responded. It would therefore seem that all the common causal organisms of ophthalmia neonatorum respond to 
penicillin therapy; no real significance can be attached to the 3 failures ( 1 gonococcus and 2 diphtheroids) in view of the satisfactory response in other (and more) cases of this type. It is also noteworthy that no failures were seen in the 7 cases in which no organism or inclusion bodies were present and in the 8 cases in which a virus appeared to be the responsible agent, judging by the presence of epithelial inclusion bodies.

At this stage it is unwarranted to draw any conclusions as to greater susceptibility of the different varieties of ophthalmia neonatorum to penicillin, but it is clear that neither the occasional failures nor relapses are explicable in terms of bacterial morphology.

A fuller account of these findings is given elsewhere (Sorsby, 1945, Sorsby and Hoffa, 1945).

2. Penicillin in 14 cases of Blepharitis.-In blepharitis penicillin in a concentration of 1,000 units per c.c. was used as a paint to the lid margins, after they had been cleansed by a solution of 10 vols. of hydrogen peroxide and the lid margins subsequently bathed in lukewarm water to remove all trace of the peroxide. Nine of these cases were mild and responded readily, giving a normal appearance within $3-8$ days; three cases were more severe but responded as readily; of the remaining 2 cases one was unilateral and associated with considerable chronic conjunctivitis and maderosis. This latter case is greatly improved-both as regards the lid margin and the conjunctivitis-but not cured after 6 weeks' treatment; the other severe case showed no conjunctivitis but heavy scale formation at the lid margins; it was clear within 14 days.

No bacteriological tests were carried out in this series as a whole, but it may be assumed that the staphylococcus aureus was the exciting organism, a supposition proved in the severe unilateral case with associated conjunctivitis.

No adequately controlled comparison with the results obtained by the use of liquor tinctorium in blepharitis has been made, but it is clear that penicillin is not inferior to liquor tinctorium.

3. Penicillin in 3 cases of trachoma.-Only one of these was a fresh case :-Bridget $G$. aged 13 years. A typical case of trachoma with follicles at the fornices and trachomatous pannus with severe corneal involvement. The child had been treated elsewhere on and off for 18 months for chronic conjunctivitis. Inclusion bodies were present in epithelial scrapings.

Apart from atropine and an initial expression the treatment consisted exclusively of once daily paintings of the tarsal conjunctiva with penicillin in a concentration of 2,500 units per c.c. This was continued for 4 weeks, but there was marked improvement within 4 days. By the end of 12 days' treatment the typical picture of trachoma had disappeared; the pannus was minimal 
and only observable with the slit-lamp. By the end of a month there was no basis for any diagnosis of trachoma. For a further month gelatine lamellae containing 200 units each were instilled nightly. Apart from roughness of the upper fornices the eyes were now normal. No further treatment has been given and the child remained under observation; the fornices assumed a normal appearance within a further 8 weeks.

A. second case represented a mild relapse of a trachoma previously treated by another surgeon by the classical methods. No definite diagnosis of trachoma could be established, but all conjunctival abnormality had disappeared within a week by daily paintings with penicillin in a concentration of 2,500 units per c.c.

The remaining case, still under treatment, is a patient with longstanding trachoma. He has had bilateral tarsectomy done (Mr. Savin). Subconjunctival injections of 1,250 units of penicillin twice weekly for 2 weeks together with daily paintings of the tarsal conjunctiva by penicillin ( 2,500 units per c.c.) have given only indefinite results.

4. Penicillin in interstitial keratitis.-Three-cases have been treated :-(1) an old-standing case in a girl aged 18 years. This had been treated extensively during the past 10 years by the classical methods, including injections of arsphenamides and tellurium. Her corneae are grossly scarred and her Wassermann reaction was never negative. She was admitted for intensive intramuscular penicillin therapy as there was some ciliary irritation. She received sixty 3 hourly doses of 666 units of penicillin per kilo bodyweight, the actual dosage being 34,500 units per injection and $2,070,000$ for the whole course. 'There was only doubtful improvement in the eye condition, but the quantitative Wassermann reaction dropped from 196 to 24 .

(2) A girl aged 14 years. She too had previously been treated. There was considerable activity in the left eye, the right being quiescent. Subconjunctival injection of 500 . units alternate days for 10 days did not appear to influence the condition, but within a fortnight there was considerable quietening.

(3) A boy aged 6 years with a clinical history and condition as that in the previous case. A course of 60 intramuscular in jections of penicillin 666 units per kilo bodyweight was given, the total being 750,000 units. There was considerable whitening of the eye noticeable as early as the 5th day of the course, but no obvious clearing of the corneal opacity of either eye by the end of the course.

\section{Discussion}

Little need be said as regards the tolerance of penicillin administered intramuscularly; the remarkably low toxicity of the drug has enabled general dosage to be elaborated with reference to 
efficacy only, and not efficacy and toxicity as with most other drugs. The marked difference in the sensitivity of different organisims to penicillin has raised the question whether a standard dosage can be laid down for clinical guidance. It would almost seem as if dosage would have to be determined by the causal organism rather than by the patient's tolerance. These and other questions in relation to the general administration of penicillin fall outside the scope of the present study. They are fully discussed in the literature on the subject.

Of more direct importance to ophthalmology are the studies on the local tolerance of the drug. It may be taken as established that high concentrations of penicillin (or rather of the penicillin now available) are not without deleterious effects on the cornea, and do moreover produce conjunctival irritation. A solution containing a concentration of 2,500 units per c.c. seems to be a safe, and in most cases an adequate, application in the form of drops. Considerable clarification is still needed as to the use of penicillin in ointment form, and in lamellae. More experience is also needed as regards the tolerance of the anterior chamber to direct injection. For the present it seems that an injection of 200 units in 0.25 c.c. is as much as is justifiable to give. Injections into the vitreous clearly require considerable care, and, at the present rate, should be practised with extreme care. It is doubtful whether it is justifiable to inject more than 100 units, or even as much. There seems to be a considerable field for the use of subconjunctival injections of penicillin, for there is fairly good tolerance to daily injection of 500 units in $\frac{1}{2}$ c.c. of water.

The use of penicillin locally is a matter of special importance in ophthalmology, not merely because it avoids more elaborate methods needed in general administration, but more significantly for the lack of evidence that any penicillin injected intramuscularly reaches the interior of the eye. The blood aqueous barrier does not, of course, prevent penicillin from reaching the conjunctiva and sclera, but these are tissues that are readily amenable to local treatment. The outstanding problem in the use of penicillin for intra-ocular infection is to get an adequate concentration of the drug into the interior of the eye. The various procedures that have been suggested, such as corneal bath, ionisation, subconjunctival injection, injection into the anterior chamber and into the vitreous, all have special difficulties and disadvantages. Pending further clarification subconjunctival injections seem to be the method of choice, though experimental evidence does not indicate that this is a particularly satisfactory method for obtaining any adequate concentration in the interior of the eye. It is unfortunate that so little is known of the surface tension and permeability of the cornea,.for with fuller knowledge of these two physical states, the possibility of obtaining adequate concentration in the interior of the eye from the local application of drops might emerge. 
In discussing tolerance and level of concentration it is of some importance to bear in mind that the normal eye of the experimental animal, and the infected eye seen in clinical practice, are not quite the same thing. There is some evidence that the impermeability of the eye to penicillin administered systemically is not so definite in the infected eye as in the healthy eye. Moreover, such intolerance as the eye shows to the injection of penicillin directly may be of subsidiary importance in comparison with the overcoming of a gross infection. Though experiments on the normal eye would indicate that intravitreal injection has to be practised with extreme caution, such treatment may be justifiable when dealing with a grossly infected vitreous. Likewise clinical results from the use of intramuscular penicillin in acute iritis and suppurative endophthalmitis are of greater significance in a final assessment than the failure to obtain any tangible concentration of penicillin in the aqueous of the normal eye of the experimental animal subjected to intramuscular injections. Studies on the infected animal eye are as yet few.

There is, as yet, no valid experimental evidence that local penicillin therapy is effective in infections of the outer eye, for the work of Robson and Scott is based on an unsatisfactory experimental lesion. The same criticism probably applies to the report by Leopold, Holmes and La Motte, who worked with a bacillus allied to the Friedlander bacillus. Until there is available an experimental lesion of the cornea that does not heal spontaneously; such studies are of limited significance. The evidence that penicillin, applied by a corneal bath and by ionisation, is effective against infection of the anterior chamber (v. Sallmann and co-workers) is more convincing. Intravitreal injection of penicillin into the experimentally infected vitreous appears to have given satisfactory results, and it is significant that the results from general administration were disappointing (Leopold). In contrast to all this uncertainty there is adequate clinical experience as to the efficacy of penicillin in the external infections of the eye. These results concern the local application of penicillin, and it is clear that both concentration and frequency of application are essential factors. This is most strikingly brought out in ophthalmia neonatorum, where concentrations of less than 2,500 units per c.c. were not found satisfactory, while the best results are obtained when drops of that concentration are put in at such frequent intervals as five minutes. In less severe infections, such as blepharitis, paints containing 1,000 units per c.c., or even less, are adequate. But it must also be borne in mind that blepharitis is generally due to staphylococcus aureus, an organism which is particularly susceptible to penicillin. Except where there is a clear indication for the use of weaker solutions, it appears that nothing is to be gained by using drops in a concentration of less 
than 2,500 per c.c. for the purulent or muco-purulent infections of the outer eye. The good results obtained by Juler and Young by the use of solid penicillin crystals in infected corneal ulcers, indicate once more the need of adequate concentration, and furthermore emphasise the uncertainty of knowledge as to the limits of tolerance of the infected eye to high concentrations of penicillin.

Pending further experience it would seem that the systemic administration of penicillin has limited value. In this respect penicillin forms a striking contrast to the sulphonamides.

The sulphonamides readily penetrate the interior of the eye, and unless means are found to influence the blood aqueous barrier, or penicillin derivatives are evolved which pass this barrier, it would seem that little can be expected from systemically administered penicillin in acute intra-ocular infections of the eye. The field of action for penicillin, would, therefore, seem to be limited for the present in the external infections and here local applications, again in contrast to the sulphonamides, are highly effective'.

It is, however, well to bear in mind that the relatively poor results obtained by the sulphonamides in the acute inflammations of the interior of the eye have raised forcibly the question of the nature of these inflammations. It is not at all sure that they are infections in the classical sense, and if indeed they are not, then little is to be expected from such developments in penicillin technique by which penicillin could reach the interior of the eye.

For the present penicillin has its widest application in those infections which have responded to general sulphonamide therapy, i.e., essentially the external infections of the eye. It bids fair to replace the sulphonamides in this limited field, and there seems to be no reason why it should not be used systemically in such cases. Penicillin also holds out the hope of controlling early purulent infections of the interior of the eye, but again by the local application rather than stystemic injection of the drug.

The outstanding non-purulent infection of the outer eye is trachoma. Here local sulphonamide therapy has proved-invaluable, possibly because the sulphonamides are not inactivated, for there is no pus. It is generally assumed that penicillin is ineffective against virus infections. Whether this also applies to the large- size virus of trachoma is not clear. Experimental proof is difficult and clinical experience is as yet too limited.

The use of penicillin in syphilitic infections of the eye would appear to be theoreticaly possible. Here too difficulties arise. In the first place the blood aqueous barrier is as likely to negative the use of penicillin in ocular syphilis as it appears to negative its use in syphilis of the central nervous system. Secondly there is little evidence that such a typical syphilitic lesion of the eye as interstitial keratitis is spirochaetal in origin. If, as is generally 
believed, interstitial keratitis is an anaphylactic reaction, the rationale for treatment by penicillin is not quite obvious.

The full exploitation of penicillin-as indeed of the sulphonamides-must await a fuller understanding of both the mechanism of the blood aqueous barrier and the nature of intra-ocular inflammation.

\section{REFERENCES}

Abraham, E. P., Chain, E.. Fletcher, C. M., Florey, H. W., Gardner A. D., Heatley, N. G. and Jennings, M. A. (1941).-Lancet, Vol. II p. 177.

Bellows, J. G. (1944).-Amer. Jl. Ophthal., Vol. XXVII, p. 1,206.

BERENS, C.- Quoted by KEYES.

BRÜCHER, E. R. (1944). -Arch. Chilenos de Oftal., Vol. I (No. 2), p. 10, and personal communication.

BURR (1944). - See MiLNER.

Cashél一, G. T.W. (1944).-Brit.Med. Jl., Vol. I, p. 420.

CRAWFORD, T. and KING, E. F (1944).-Brit. Ji. Ophthal., Vol. XXVIII, p. 373.

DunNington, J. H. and von Sallman, L. (1944).-Arch. Ophthal., Vol. XXXII, p. 353.

Elliot , A. J. (1944).-Canadian Med. Assoc. Jl., Vol. LI, p. 257.

Florey. M. E. and Florey, H. W. (1943). - Lancet, Vol. I, p. 387.

Florey, M. E., MACFARLAN, A. M. and MANN, I. (1945).-Brit. Jl. Ophthal., Vol. XXIX, p. 333.

Gilfor D, G. H. (1945).-Brit. Med. Jl., Vol. I, p. 232.

GOLDBERG, H. K. (1945).-Arch Ophthal., Vol. XXXIII, p. 406.

GRANT (1944).-Quoted by KEYES.

Green, M. I. and Jakobovits, R. (1945).-Amer. Jl. Ophthal., Vol. XXVIII, p. 191.

GRIFFeY, W. P. (1944).-Arch. Ophthal., Vol. XXXI, p. 162.

JULER F. and Young, M. Y. (1945).-Brit. Jl. Ophthal., Vol. XXXIX, p. 312.

KeYes, J. E. L. (1944).-Jl. Amer. Med. Assoc., Vol. CXXVI, p. 610.

LA RoccA, V. (1945).-Amer. Jl. Ophthal., Vol. XXVIII, p. 183.

LEMoINe, A. N. L. and Lemoine, A. N. (1944).-Ibid., Vol. XXVII, p. 1428.

LEOPOLD, I. H. (1945).-Arch. Ophthal., Vol. XXXIII, p. 211.

LeOPOLd, I. H., Holmes and LA MOTTE, W. O. (1945).-Arch. Ophthal., Vol. XXXII; p. 193.

LEOPOLD, I. H. and LA Motte (1945).-Arch. Ophthal., Vol. XXXIII, p. 43.

Mietus, C. A. (1945).-Amer. Jl. Ophthal., Vol. XXVIII, p. 173.

MilNer, J. G. (1944).-Brit. Med.Jl., Vol. II, p. 175.

NeEly, J. C. and Cross, A. G. (1945).-Lancet, Vol. I, p. 85.

Palin (1944).-See Milner.

Rammelkamp, C. H. and Keefer, C. S. (1943).-Jl. Clin. Invest., Vol. XXII, p. 425 .

Robson, M. and ScotT, G. I. (1943).-Lancet, Vol. I, p. 100 ; Brit. Jl. Exper. Path., Vol. XXIV, p. 50.

RYCrofT, B. W. (1945).-Brit. Jl. Ophthal., Vol. XXIX; p. 57.

von Sallman N, L. (1943).-Arch. Ophthal., Vol. XXX, p. 426.

- (1944a).-Arch. Ophthal., Vol. XXXI, p. 54.

(1944b).-Arch. Ophthal., Vol. XXXII, p: 190.

von SallmanN, L. and MEYER, K. (1944).-Arch. Ophthal., Vol. XXXI, p. 1.

von SallmanN, L., MEYer, K. and Di Grandi, J. (1944).-Arch. Ophthal., Vol. XXXII, p. 179.

SAMPSON (1944). - See MILNER.

Sievers, J. J., KNott, L. W. and Soloway, H. M. (1944).-Jl. Amer. Med. Assoc., Vol. CXXV, p. 690.

SOMERVILLE-LARGE, L. B. (1945).--Personal communication.

SorSBY, A., HofFA, E. E. (1942).-Brit. Med. Jl., Vol. I, p. 114.

SorsBy, A. (1945). -Brit. Med. Jl., Vol. I, p. 691 .

Struble, E. C. and Bellows, J. G. (1944).-Jl. Amer. Med. Assoc.,Vol. CXXV, p. 685 . 